\title{
BMJ Open What might interrupt men's suicide? Results from an online survey of men
}

\author{
Fiona L Shand, ${ }^{1,2,3}$ Judy Proudfoot, ${ }^{1,2,3}$ Michael J Player, ${ }^{1,3}$ Andrea Fogarty, ${ }^{1,3}$ \\ Erin Whittle, ${ }^{1,3}$ Kay Wilhelm, ${ }^{1,2,3,4}$ Dusan Hadzi-Pavlovic, ${ }^{1,3}$ Isabel McTigue, ${ }^{1,3}$ \\ Michael Spurrier, ${ }^{5}$ Helen Christensen ${ }^{1,2,3}$
}

To cite: Shand FL,

Proudfoot J, Player MJ, et al. What might interrupt men's suicide? Results from an online survey of men. BMJ Open 2015;5:e008172. doi:10.1136/bmjopen-2015008172

- Prepublication history and additional material is available. To view please visit the journal (http://dx.doi.org/ 10.1136/bmjopen-2015008172).

Received 12 March 2015 Revised 10 September 2015 Accepted 14 September 2015

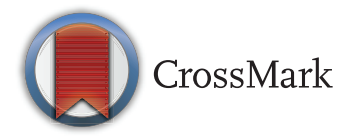

${ }^{1}$ Black Dog Institute, Sydney, New South Wales, Australia ${ }^{2}$ NHMRC Centre for Research Excellence in Suicide Prevention, Sydney, New South Wales, Australia

${ }^{3}$ Faculty of Medicine, University of New South Wales, Sydney, New South Wales, Australia

${ }^{4}$ Faces in the Street, O'Brien Centre, St Vincent's Hospital, Sydney, New South Wales, Australia

${ }^{5}$ University of New South Wales, Sydney, New South Wales, Australia

Correspondence to Dr Fiona L Shand; fionas@unsw.edu.au

\section{ABSTRACT}

Objectives: Men are almost two times more likely to die by suicide than women, yet little research has focused on what is required to prevent suicide among men. This paper aims to investigate what factors interrupt suicidal behaviour in men, and to examine differences according to known suicide risk factors.

Setting: Australia.

Participants: 251 Australian men aged 18 years and over who had made a suicide attempt 6-18 months prior to completing the survey.

Outcomes: The survey canvassed the language men use to describe their depression and suicidality, warning signs, barriers to accessing help and what is needed to interrupt a suicide attempt. ORs and $\chi^{2}$ were used to test for differences by age, geographic location and current depression severity.

Results: Of 299 men screened and eligible to participate, 251 completed all or part of the survey. Participants identified different words and warning signs for depression compared with suicidality. The most commonly endorsed barriers to accessing help were not wanting to burden others $(66 \%)$ and having isolated themselves (63\%). Men overwhelmingly endorsed 'I thought about the consequences for my family' as the factor which stopped a suicide attempt $(67 \%)$. 'I need support from someone I really trust and respect' was also strongly endorsed. There were few differences by age, region or depression severity.

Conclusions: Participants were able to identify signs, albeit often subtle ones, that they were becoming depressed or suicidal. Similarly, most were able to identify active strategies to interrupt this downward spiral. Men wanted others to notice changes in their behaviour, and to approach them without judgement.

\section{INTRODUCTION}

Around $75 \%$ of suicide deaths in Australia are men. Suicide is the leading cause of death among Australian men aged 18-44 years, ${ }^{1}$ and is particularly prevalent among men who are separated or divorced, unemployed, experiencing ill health, chronic pain, mental illness and substance use disorders. $^{2}{ }^{3}$ Globally, men are almost two times

\section{Strengths and limitations of this study}

- This was a mixed methods study with substantial input from people with lived experience into the quantitative survey.

- This was a convenience sample of participants and not a representative sample.

- These men may differ from other men, who did not see or respond to the survey, in important ways such as their coping strategies and suicidal intent.

more likely to die by suicide than women, with intercountry ratios ranging from 0.9 to 4.1. ${ }^{3}$ In Australia, men in regional and rural areas are particularly at risk. ${ }^{4}$

Although men have lower reported rates of mood and anxiety disorders, suicidal ideation and suicide attempts than women, they have higher rates of risk-taking, impulsivity and substance use disorders. ${ }^{5}$ These are factors which put them at risk of progressing from suicidal thinking to a suicide attempt. ${ }^{6}$

Further gender differences are evident in help-seeking and coping strategies. Men seek help for depression and suicidality less often. $^{7}$ Of the men who reported a 12-month mental disorder in 2007, only $27 \%$ sought professional assistance, compared with $41 \%$ of women. ${ }^{8}$ Suicidal males have a higher threshold for help-seeking than women. $^{7}$ In the 12 months prior to suicide, fewer men than women sought help from a mental health professional or primary care providers. ${ }^{9}$ Young women also have greater social support and are more likely to use it than young men, in addition to being more likely to 'vent' or turn to religion. ${ }^{10}$ With increased isolation a risk factor for suicidality, seeking social support is likely to be an effective protective behaviour for women. One further difference likely to have a substantial impact on the gender difference in suicide deaths is men's choice of more lethal means, which goes some way to explaining 
why women have more suicide attempts but fewer deaths. ${ }^{11}$

Despite the scope of the problem for men, little is known about how to prevent men's suicidal behaviours or how to interrupt a man's suicide attempt. Even less research has examined this issue from the perspective of those with lived experience. ${ }^{12}$ The current study aims to address this gap. Specifically, it aims to:

1. Investigate what factors interrupt suicidal behaviour and contribute to taking action during a suicidal crisis;

2. Examine differences according to known risk factors for death by suicide: regional or remote geographic location, older age and higher depression severity.

\section{METHOD}

\section{Design}

As part of a mixed-method study investigating men's experiences of depression and suicidality, two online surveys were conducted with (1) men who had made a suicide attempt in the previous 6-18 months and (2) family or friends of men who had made a suicide attempt between 6 and 18 months prior to survey participation. Data reported here are from the men's survey only. The survey items were derived from themes emerging from phase 1 of the study, a qualitative project, where men took part in interviews and family and friends took part in focus groups examining what factors contribute to suicidal behaviour and depression and what interrupts suicidal behaviour. ${ }^{13}$ The wording used for the questions and responses came from the language used by the men during their interviews.

\section{Participants}

Participants were screened online and were required to be male, aged 18 years or over, living in Australia and to have had a suicide attempt in the past 6-18 months. This time frame was chosen to ensure accurate recall on the one hand, and to minimise the risk that participants remained actively suicidal and vulnerable on the other. Participants were recruited through a national publicity campaign. The project was publicised nationally through our partner organisations beyondblue, Faces in the Street and Men's Sheds Australia, and through the Black Dog Institute's website and social media channels (Facebook and Twitter), Lifeline, state and territory consumer and carer networks, mental health professional networks and suicide prevention organisations.

\section{Survey instrument and measures}

The survey collected data on demographics (age, postcode, marital status, employment status, Aboriginal/ Torres Strait Islander status, self-reported general health and educational attainment: see online supplementary material). The presence and severity of depression was assessed using the Patient Health Questionnaire 9 (PHQ-9). The PHQ-9 is a nine-item self-administered scale which assesses how often in the past 2 weeks participants have been bothered by a range of symptoms or problems. ${ }^{14}$ Current level of depression used the standardised PHQ-9 categories whereby $1-4$ is minimal depression, 5-9 is mild, 10-14 is moderate, 15-19 moderately severe and 20-28 severe. Anxiety was assessed using the Generalised Anxiety Disorder 7 (GAD-7) Scale. The GAD-7 is a seven-item self-administered scale used to assess the severity of generalised anxiety by asking how often participants have experienced symptoms in the previous 2 weeks. ${ }^{15}$ Both scales have good reliability and validity. ${ }^{14}{ }^{15}$ Current level of anxiety used the standardised GAD-7 categories where $0-4$ is no or minimal anxiety, 5-9 is mild, 10-14 is moderate and 15-21 severe. Participants were also asked if they were currently receiving treatment and/or had ever received treatment for depression, anxiety or stress.

For the online survey, the response categories for each question described below were drawn from the phase 1 interviews and focus groups. All questions allowed for an 'other' response followed by free text. Participants were asked to select a response to each of the following questions:

1. What words do you use to describe when you are feeling (a) down in the dumps and (b) that life is not worth living? (select all that apply);

2. What changes would people have seen when you were feeling really down and that life was not worth living? (the response scale was 'strongly agree' to 'strongly disagree' with 'strongly agree' and 'agree' dichotomised into 'agree' and all other responses coded as 'disagree');

3. When you were feeling down in the dumps, what got in the way of you seeking help? (select all that apply);

4. When you've felt that life was not worth living, what was it that stopped you from making a suicide attempt? (the response scale was 'strongly agree' to 'strongly disagree' with 'strongly agree' and 'agree' dichotomised into 'agree' and all other responses coded as 'disagree');

5. What else is needed to interrupt a suicide attempt? (the response scale was 1-5 with 5 being extremely important and 1 being not at all important, with 1-3 coded as unimportant and 4-5 as important);

6 . In your opinion, what is the best way to get information and strategies to men and their family and friends? (select one or more options).

The survey was initially tested for length and clarity with a small number of participants. It was then modified and retested using the Think Aloud Method, which is designed to identify participants' thought processes while they complete the survey. ${ }^{16}$ Participants are asked to complete the survey and as they do so, to verbalise their thoughts, with a researcher listening to them 'thinking aloud' without being directly addressed by the participant. The researcher also observes the participant's non-verbal behaviours (sighing, pauses, slouching, taking a long time on a question, having to read a 
question more than once). This feedback was used to modify the survey before its release. The final survey was built and administered online using QuestionPro. ${ }^{17}$

\section{Participant safety}

Screening excluded those who had made a suicide attempt in the past 6 months. People who were ineligible as well as any participants who were distressed could enter their contact details in order to be contacted directly by Lifeline, who were contracted to provide special follow-up services for the study. Participants were asked at the beginning and end of the survey to rate their level of sadness, irritability, anxiety and agitation on a 0 to 10 scale. A rating of 8 or more triggered a webpage expressing concern about their level of distress and where participants could enter their contact details to receive contact from Lifeline. The same page was triggered if participants scored in the severe range on the PHQ-9 or GAD-7, or indicated on PHQ-9 question 9 that they had had suicidal ideation in the past 2 weeks. There was no change in the mean score on the emotional rating scales administered at the beginning and end of the survey.

\section{Statistical analysis}

Proportions are presented as percentages. ORs and $\chi^{2}$ were used to test for differences at $\mathrm{p}<0.05$. Statistical analysis was completed in SPSS. The analysis by region used postcode classified using the Australian Standard Geographical Classification-Remoteness Area. ${ }^{18}$ Owing to small numbers in the very remote, remote and outer regional categories, three categories were used: Major cities, inner regional and outer regional/remote. Participants were classified by age groups 18-24, 25-34, $35-44,45-54$ and 55 years and over. This last category was used because of very small numbers in the 65 years and over age group.

\section{RESULTS}

\section{Participant characteristics}

299 men completed screening and were eligible to participate. Of these, 251 men completed all or part of the survey (an $84 \%$ participation rate). Data reported below are from these 251 men. Participants had a mean age of 36.9 (SD 11.6). One-third (34\%) were married or in a de facto relationship, $59 \%$ were in paid employment, one-quarter $(24 \%)$ of participants were unemployed or unable to work, and one-quarter $(26 \%)$ had completed a university degree. The mean PHQ-9 score was 14.4 (SD 10.4) (moderate range), and the mean GAD-7 was 7.0 (SD 5.9) (mild range). Seventy per cent rated their general health as good, very good or excellent, and 30\% as fair or poor. Fifty per cent were currently receiving treatment for depression, $36 \%$ for anxiety and $19 \%$ for stress, while $24 \%$ were receiving no treatment. Overall, two-thirds of participants were receiving treatment for at least one condition and more than half of the participants $(54 \%)$ were receiving treatment for two or more conditions. Sixty-one per cent had previously received treatment for depression, $47 \%$ for anxiety and $28 \%$ for stress. Fifty-five per cent endorsed 'thoughts that you would be better off dead or of hurting yourself' in the past fortnight, as per PHQ-9 item 9.

\section{Words to describe feeling depressed or suicidal}

Men endorsed different words or phrases to describe each state. The most frequently endorsed words or terms to describe when they were feeling suicidal were: useless or worthless, I've had enough, hopeless, pointless and over it (table 1). To describe feeling depressed, the most frequently nominated words or terms were: stressed, tired, not going too well and down in the dumps.

\section{Signs of depression and suicidality}

The behaviours that men commonly said others might have noticed when they were feeling down or suicidal were: loss of interest in everything, shutting themselves away, changes in sleep and poor self-care, followed by being flustered or easily upset and irritable (table 2). Fewer men nominated the more overt signs of suicidality such as telling people how they were feeling or saying goodbye to those close to them. Nevertheless, these men constituted a substantial minority of the sample.

Few differences in signs were identified by age, geographic location or current severity of depression. Those in the 18-24 year age group were more likely to endorse I was taking more risks ( $74 \%$ vs $28 \%$ in the 55 years and over age group, $\left.\chi^{2}=12.6, \mathrm{p}<0.05\right)$. There were no other age-related differences in the signs of depression and suicidality. Those living in outer regional or remote areas were more likely to endorse $I$ was more aggressive towards others $\left(88 \%\right.$ vs $66 \%$ in major cities; $\chi^{2}=8.04$, $\mathrm{p}<.05$ ); while those living in inner regional areas were

Table 1 Words men use to describe feeling suicidal or depressed $(n=192)$

\begin{tabular}{lll}
\hline Words & $\begin{array}{l}\text { I use this to } \\
\text { describe when } \\
\text { I'm feeling } \\
\text { suicidal, \% }\end{array}$ & $\begin{array}{l}\text { I use this to } \\
\text { describe when } \\
\text { I'm feeling } \\
\text { depressed, \% }\end{array}$ \\
\hline Useless or worthless & 74 & 30 \\
I've had enough & 69 & 30 \\
Hopeless & 68 & 27 \\
Pointless & 66 & 25 \\
Over it & 62 & 36 \\
Lost & 54 & 35 \\
Fed up & 48 & 35 \\
Tired & 42 & 52 \\
Not going too well & 30 & 56 \\
Deeply sad & 33 & 30 \\
Stressed & 26 & 56 \\
Angry & 22 & 42 \\
Down in the dumps & 9 & 52 \\
\hline
\end{tabular}


Table 2 Signs of depression and suicidality $(n=176)$

\begin{tabular}{ll}
\hline Signs & Per cent \\
\hline I lost interest in everything & 86 \\
I shut myself away & 84 \\
I was sleeping more or less than usual & 84 \\
I was not eating well or taking care of myself & 83 \\
I was flustered, easily upset & 81 \\
I was irritable & 79 \\
I was on autopilot & 70 \\
I was more aggressive towards others & 57 \\
I was taking more risks & 52 \\
I was drinking more alcohol & 49 \\
I was using more drugs & 27 \\
I told one or more people how I was feeling & 43 \\
I said goodbye to people & 38 \\
\hline
\end{tabular}

less likely to endorse I told one or more people how I was feeling (27\% vs $48 \%$ in major cities and $47 \%$ in outer regional or remote areas; $\left.\chi^{2}=6.4, \mathrm{p}<0.05\right)$. Those with PHQ-9 scores in the moderately severe and severe ranges were more likely to endorse I said goodbye to people ( $49 \%$ and $45 \%$, respectively, vs $28 \%$ mild and $23 \%$ moderate depression, $\left.\chi^{2}=9.2, \mathrm{p}<0.05\right)$.

\section{Barriers to accessing help}

The most frequently nominated barrier to getting help was not wanting to be a burden to others, followed by having distanced one's self from everyone, a tendency to bottle up feelings and a sense that everything seemed pointless (table 3). One in six men said that they did not know where to get help. Only $8 \%$ of the men surveyed said that there were no barriers to seeking help.

One barrier to accessing help differed by age group, with those aged 18-24 years more likely to endorse $I$ didn't want to burden others $\left(77 \%\right.$ vs $66 \%, \chi^{2}=10.7$, $\mathrm{p}<0.05)$. The only difference in barriers to accessing help by region was I was worried that I might be hospitalised, endorsed more strongly by $60 \%$ of those in inner regional areas compared with $42 \%$ in major cities and $27 \%$ in outer regional and remote areas $\left(\chi^{2}=5.8\right.$, $\mathrm{p}<0.05)$. Those with more severe depression were more likely to endorse I didn't want to burden others $(72 \%$ severe and $88 \%$ moderately severe categories vs $57 \%$ mild and $68 \%$ moderate categories; $\chi^{2}=11.5, p<0.05$ ) and I was worried that I might be hospitalised $(61 \%$ severe and $60 \%$ moderately severe categories vs $26 \%$ mild and $31 \%$ moderate categories; $\chi^{2}=13.2, \mathrm{p}=0.01$ ).

\section{What interrupted or stopped a suicide attempt?}

When asked what stopped them from attempting suicide, the most strongly endorsed factor was by far thinking about the consequences for family (table 4). This theme of concern for others was apparent in other strongly endorsed factors: just over half agreed or strongly agreed that not wanting to put the burden on someone finding them was a barrier to suicide, followed by
Table 3 Barriers to accessing help $(n=176)$

\begin{tabular}{ll}
\hline Barriers to accessing help & Per cent \\
\hline I didn't want to burden others & 66 \\
I had distanced myself from everyone & 63 \\
I just couldn't see the point in getting any help & 57 \\
I tend to bottle up my feelings and it's hard for & 58 \\
me to talk about it & 45 \\
It was my responsibility to handle it & 45 \\
Suicide was my go to plan and I wasn't going & \\
to let go of that & 45 \\
I was worried that I might be hospitalised & 43 \\
I had no one around me that I could talk to & 36 \\
Society's view of men-this expectation that \\
men are tough and should be able to deal with \\
their own issues \\
The service (eg, doctor, psychologist, \\
counsellor) I tried wasn't helpful \\
$\begin{array}{l}\text { At the time I couldn't see how bad things really } \\
\text { were }\end{array}$ & 33 \\
I wanted someone to help but I wouldn't ask & 32 \\
for it & \\
I didn't want to accept help-that's not me & 28 \\
I didn't know where to go for help & 17 \\
Nothing-I was able to seek help & 8 \\
\hline
\end{tabular}

half of the respondents endorsing not wanting people to feel it was their fault. More than one-third said that having a friend or family member express their concern and then follow up with support stopped them from attempting suicide. When asked to nominate the most important factor, consequences for family was again the most frequently nominated at $32 \%$.

I didn't want to put the burden on someone finding me was more likely to be a barrier for those in the 18-24 year age group $(66 \%)$ and the $45-54$ year age group (64\%)

Table 4 What interrupts a suicide attempt? $(n=176)$

\begin{tabular}{ll}
\hline Interrupting factors & Per cent \\
\hline I thought about the consequences for my & 67 \\
family & \\
I didn't want to put the burden on someone & 54 \\
finding me & \\
I didn't want the people left behind to feel like it & 48 \\
was their fault & \\
I need to be here for others & 38 \\
A friend/family member who was concerned & 35 \\
followed up & 37 \\
Being able to talk to someone & 30 \\
I broke the downward spiral by asking for help & 30 \\
Someone gave me some hope & 27 \\
I was afraid of dying & 26 \\
I really don't want to die & 25 \\
My kids wouldn't know me if I died now & 23 \\
Knowing that I was valued & 19 \\
Good friends spent a lot of time with me & 13 \\
I believe it's wrong & 13 \\
I had a specific commitment to someone else & \\
\hline
\end{tabular}


than in the 25-34 year age group $(47 \%)$ or the 55 years and over age group $(28 \%) ;\left(\chi^{2}=9.2, \mathrm{p}<0.05\right)$. I had a specific commitment to help someone else was endorsed more by those in the 18-25 year age group (34\%) compared with the overall endorsement rate $(13 \%)\left(\chi^{2}=19.9, p=0.001\right)$. There were no differences by region. Being able to talk to someone was more commonly endorsed by those with no or minimal depression $(56 \%)$, moderately severe depression $(53 \%)$ or severe depression $(59 \%)$ compared with those with mild $(28 \%)$ or moderate depression scores $(37 \%) \quad\left(\chi^{2}=10.3, \mathrm{p}<0.05\right)$. Knowing that I was valued was endorsed more frequently by those with no depression (56\%) or mild depression (48\%) compared with those with moderate $(31 \%)$, moderately severe $(29 \%)$ or severe depression $(27 \%) \quad\left(\chi^{2}=9.6, \mathrm{p}<0.05\right)$. Finally, those with severe depression scores were more likely to endorse I had a specific commitment to help someone else (25\%) compared with those with mild, moderate or moderately severe depression $(7 \%, 6 \%$ and $10 \%$, respectively; $\left.\chi^{2}=9.7, \mathrm{p}<0.05\right)$.

\section{What else is needed to interrupt a suicide attempt?}

Men were asked what else was needed to interrupt a suicide attempt (table 5). A large majority of men (86\%) endorsed I need support from someone I really trust

Table 5 What else is needed to interrupt a suicide attempt? $(n=150)$

\begin{tabular}{|c|c|}
\hline Item & Per cent \\
\hline $\begin{array}{l}\text { I need support from someone I really trust and } \\
\text { respect }\end{array}$ & 86 \\
\hline $\begin{array}{l}\text { Don't tell me that everything will be okay. Ask } \\
\text { me to tell you what's up and then listen with an } \\
\text { open mind }\end{array}$ & 82 \\
\hline $\begin{array}{l}\text { I need to know that others can hear the truth } \\
\text { and they won't judge me }\end{array}$ & 76 \\
\hline $\begin{array}{l}\text { Someone needs to notice the changes they're } \\
\text { seeing in me, for example, withdrawal, } \\
\text { irritability }\end{array}$ & 75 \\
\hline $\begin{array}{l}\text { We need to let men know that others are going } \\
\text { through this too, it's normal to struggle } \\
\text { sometimes, and there is help }\end{array}$ & 74 \\
\hline $\begin{array}{l}\text { You need to be very direct and tell me you } \\
\text { know what's going on for me. Then support me } \\
\text { to get more help }\end{array}$ & 59 \\
\hline $\begin{array}{l}\text { Help me to break my problems down into } \\
\text { smaller pieces and then set some goals }\end{array}$ & 58 \\
\hline $\begin{array}{l}\text { Get me involved in something bigger than } \\
\text { myself, like helping others who are worse off }\end{array}$ & 54 \\
\hline $\begin{array}{l}\text { Encourage me to do more things for myself, } \\
\text { like taking care of myself }\end{array}$ & 52 \\
\hline $\begin{array}{l}\text { Talking to a friend can be easier than family } \\
\text { because they're one step removed. There's not } \\
\text { so much pressure to get well quickly }\end{array}$ & 48 \\
\hline $\begin{array}{l}\text { Friends and/or family have to get in my face, } \\
\text { and stay there because I'm probably not going } \\
\text { to ask for help }\end{array}$ & 48 \\
\hline
\end{tabular}

and respect. The kind of support was also important, with men saying they did not want to be told that everything will be okay-rather, they wanted someone to listen with an open mind, and to know that the person can hear the truth without judging them. Around three-quarters of men said it was important to hear that others are going through this too and that it is normal to struggle sometimes. More than two-thirds wanted others to notice the changes that they were seeing (eg, withdrawal, irritability).

There were no differences by age group or region. Those with mild depression or severe depression scores were more likely to endorse Get me involved in something bigger than myself, like helping others who are worse off $(76 \%$ and $61 \%$, respectively) compared with those with no depression (36\%), moderate depression $(49 \%)$ or moderately severe depression scores $(43 \%) \quad\left(\chi^{2}=12.6\right.$, $\mathrm{p}<0.05)$.

Endorsement of Don't tell me that everything will be okay. Ask me to tell you what's up and then listen with an open mind was more likely among participants with severe depression $(91 \%)$ or moderate depression $(91 \%)$ compared with those with mild depression $(69 \%)$ or moderately severe depression $(71 \%) \quad\left(\chi^{2}=13.8, \mathrm{p}<0.01\right)$.

\section{Best ways to disseminate information to men who are experiencing depression or suicidality}

The following strategies, in order, were endorsed to get information to men: high profile men talking in the mainstream media about their experience of depression and suicidality; an ad campaign directed at men, using social media to distribute information and having a central online source of information about depression and suicidality (table 6).

\section{DISCUSSION}

This study contributes to our understanding of the language men use, the barriers to accessing help and strategies to interrupt the path to a suicide attempt. With more than half the sample reporting suicidal ideation in the past 2 weeks, this group of men remain substantially impaired compared to the general population, with

Table 6 Strategies to disseminate information to men $(n=150)$

\begin{tabular}{ll}
\hline Source & Per cent \\
\hline High profile men in mainstream media & 53 \\
Ad campaign directed at men & 46 \\
Facebook or other social media & 43 \\
Central online source of info & 39 \\
Education campaign through general & 20 \\
practitioners & \\
Online ads & 18 \\
Online chat rooms & 11 \\
\hline
\end{tabular}


12 month prevalence rates for suicidal ideation of $6-8 \%$ reported in general population surveys. ${ }^{19}$ Despite a similar level of educational attainment to that in the wider Australian population, one-quarter of the sample were unemployed or unable to work, an employment rate much higher than the current Australian average of $6.3 \% .^{20}$

Important to identifying depression and suicidality in men is understanding the language they use to describe it. The words endorsed by men to describe suicidality were different from those used to describe depression. The terms used to describe suicidality seem indicative of greater despair (useless or worthless, I've had enough, hopeless, pointless and over it) when compared with the language used to describe depression (stressed, tired, not going too well and down in the dumps).

The overt signs of depression and suicidality were the least commonly endorsed. The behaviours that men commonly said others might have noticed when they were feeling down or suicidal were centred on emotional or social withdrawal: changes in sleep, shutting themselves away, loss of interest in everything and poor self-care. The next most commonly endorsed group of behaviours was signs of emotional disturbance: being flustered or easily upset and irritable. It is likely that this group of changes would be easily misinterpreted by friends and family. A third group which could be characterised as externalising behaviours-aggression, risk-taking, using alcohol and other drugs-was less frequently endorsed. Being more aggressive towards others was more commonly endorsed by those in outer regional or remote areas, and risk-taking by younger men, findings worth noting for both clinical and public education purposes. Fewer men nominated the more overt signs of suicidality such as telling people how they were feeling or saying goodbye to those close to them; these signs were nevertheless endorsed by a substantial minority.

The two most commonly endorsed barriers to helpseeking-I didn't want to burden others and I had distanced myself from everyone-are consistent with the Interpersonal-Psychological Theory of suicide, which posits that perceived burdensomeness and thwarted belongingness are necessary for suicidal thinking. ${ }^{21}{ }^{22}$ As such, both of these factors seem likely targets for interventions to (1) increase help-seeking and (2) reduce suicidal ideation.

Concern for others (thinking about the consequences for family, not wanting to put the burden on someone finding them, not wanting people to feel it was their fault) was most frequently identified as an interrupting factor and might be considered a psychological factor which can be enhanced. This finding needs to be interpreted within the context of another, that is, that men want others to listen without judgement. Support from trusted and respected people, offered in the right way, was strongly endorsed. So while men might be asked to identify their reasons for living, it is important that men are not made to feel guilty or 'selfish' for thinking about suicide.

There were few differences by age, though the youngest age group (18-24 years) showed more differences than any other age group. Similarly, there were few variations across different levels of population density. There were several differences identified amongst those with more severe depression, some of which appeared to centre around focusing on others' needs. Participants with more severe depression were more likely to endorse two factors that would interrupt a suicide attempt: 'Get me involved in something bigger than myself, like helping others who are worse off' and one barrier to accessing help: 'having a specific commitment to helping someone else' as factors which interrupt a suicide attempt; and 'not wanting to burden others'. These findings would benefit from further exploration. Nevertheless, the overall findings were remarkably similar across age groups, region and severity of depression.

\section{Limitations}

It is important to note that this was a convenience sample of participants and not a representative sample. These men may differ from other men, who did not see or respond to the survey, in important ways such as their coping strategies and suicidal intent. For instance, two-thirds of our participants were receiving treatment for depression, anxiety or stress, compared with $27 \%$ of men with a mental health disorder in the general population. ${ }^{23}$ A potential limitation of the study is that we used current levels of depression when assessing the impact of depression severity on motivations and barriers to seeking help. Severity of depression at the time the man was suicidal may be a better predictor of these factors. It is also possible that participants' retrospective thinking about their suicide attempt may be influenced by their current levels of depression.

\section{Implications and conclusions}

The men in this study were able to identify warning signs that they were becoming depressed or suicidal. The signs most commonly endorsed were subtle behavioural changes rather than overt statements of distress. Similarly, most men were able to identify active strategies to interrupt this downward spiral. Men were particularly concerned about the impact that their suicide would have on their family. Importantly, they were open to being approached by people they trusted and respected. Men wanted them to listen without judgement and without offering reassurance that everything would be okay. There were remarkably few differences in these findings by age, region or depression severity. While the findings of this study need to be confirmed using larger sample sizes, they point to potential intervention targets: education for health professionals and for those who are concerned about a male friend or family member regarding warning signs and the language used by men 
to describe suicidality; the potential for cognitive intervention regarding perceived burdensomeness as a way to increase help-seeking; behavioural interventions to reduce men's isolation at critical times; and interventions for family and friends regarding how to approach men about whom they are concerned. Finally, while there were no overwhelmingly endorsed strategies for disseminating information to men, the most strongly endorsed strategies focused on a male-specific campaign with high profile men talking in the mainstream media about their experience of depression and suicidality, suggesting that stigma reduction campaigns continue to be important.

\section{Twitter Follow Andrea Fogarty at @AndreaFogartyPH}

Contributors FLS led the design of the online survey, drafted the manuscript and led the data analysis. JP, AF, KW, DH-P and HC contributed to the design of the larger project and MS to the qualitative component. MJP, AF, EW and IM assisted with the design, programming and piloting of the online survey. DHP advised on data analysis. All authors contributed to revising drafts of the manuscript.

Funding The study was funded by beyondblue and the Movember Foundation.

Competing interests None declared.

Ethics approval Ethics approval for the research was provided by the UNSW Human Research Ethics Committee (HREC 13077).

Provenance and peer review Not commissioned; externally peer reviewed.

Data sharing statement No additional data are available.

Open Access This is an Open Access article distributed in accordance with the Creative Commons Attribution Non Commercial (CC BY-NC 4.0) license, which permits others to distribute, remix, adapt, build upon this work noncommercially, and license their derivative works on different terms, provided the original work is properly cited and the use is non-commercial. See: http:// creativecommons.org/licenses/by-nc/4.0/

\section{REFERENCES}

1. Australian Bureau of Statistics. Causes of Death, Australia, 2012, Catalogue 3303.0. Canberra: ABS, 2014. http://www.abs.gov.au/ AUSSTATS/abs@.nsf/DetailsPage/3303.02011?OpenDocument

2. Nock MK, Borges G, Bromet EJ, et al. Cross-national prevalence and risk factors for suicidal ideation, plans and attempts. Br J Psychiatry 2008;192:98-105.

3. World Health Organization. Preventing suicide: a global imperative. Geneva: World Health Organization, 2014.
4. Australian Institute of Health and Welfare. Rural, regional and remote Australia:a study on mortality. 2nd edn. Canberra: AlHW, 2007 Contract No.: Cat. no. PHE 95.

5. Slade T, Johnston A, Teesson M, et al. The Mental Health of Australians 2. Report on the 2007 National Survey of Mental Health and Wellbeing. Canberra: Department of Health and Ageing, 2009.

6. Nock MK, Hwang I, Sampson NA, et al. Mental disorders, comorbidity and suicidal behavior: results from the National Comorbidity Survey Replication. Mol Psychiatry 20010;15:868-76.

7. Biddle L, Gunnell D, Sharp D, et al. Factors influencing help seeking in mentally distressed young adults: a cross-sectional survey. Br J Gen Pract 2004;54:248-53.

8. Slade T, Johnston A, Oakley Browne MA, et al. 2007 National Survey of Mental Health and Wellbeing: methods and key findings. Aust N Z J Psychiatry 2009;43:594-605.

9. Luoma JB, Martin CE, Pearson JL. Contact with mental health and primary care providers before suicide: a review of the evidence. Am J Psychiatry 2002;159:909-16.

10. Renk K, Creasey G. The relationship of gender, gender identity, and coping strategies in late adolescents. J Adolesc 2003;26:159-68.

11. Dombrovski AY, Szanto K, Duberstein $P$, et al. Sex differences in correlates of suicide attempt lethality in late life. Am J Geriatr Psychiatry 2008;16:905-13.

12. SANE Australia, England UoN. Lessons for Life. The experiences of people who attempt suicide: a aualitative research report. South Melbourne: SANE Australia, 2015.

13. Player MJ, Proudfoot J, Fogarty A, et al. What interrupts suicide attempts in men: a qualitative study. PLOS ONE 2015;10:e0128180.

14. Kroenke K, Spitzer RL, Williams JB. The PHQ-9: validity of a brief depression severity measure. $J$ Gen Intern Med 2001;16:606-13.

15. Spitzer RL, Kroenke K, Williams JB, et al. A brief measure for assessing generalized anxiety disorder: the GAD-7. Arch Intern Med 2006;166:1092-7.

16. Maarteen W, van Someren YFB, Jacobijn AC, et al. The think aloud method: a practical guide to modelling cognitive processes. London: Academic Press, 1994.

17. Questionpro. Questionpro website. 2015. http://www.questionpro. com/au/

18. Australian Bureau of Statistics. Australian Statistical Geography Standard (ASGS) Volume 5-Remoteness Areas, Catalogue no. 1270.0.55.005. Canberra: ABS, 2011.

19. Fairweather-Schmidt AK, Anstey KJ, Salim A, et al. Baseline factors predictive of serious suicidality at follow-up: findings focussing on age and gender from a community-based study. BMC Psychiatry 2010;10:41

20. Australian Bureau of Statistics. Labour Force, Australia. Canberra: ABS, January 2015. http://www.ausstats.abs.gov.au/ausstats/ meisubs.nsf/0/106D4260571CAD53CA257EBB0021B8E1/\$File/ 62020 Aug\%202015.pdf (accessed 27 Mar 2015).

21. Rooney R, Hassan S, Kane R, et al. Reducing depression in 9-10 year old children in low SES schools: a longitudinal universal randomized controlled trial. Behav Res Ther 2013:51:845-54.

22. Joiner T. Why people die by suicide. Cambridge, MA, US: Harvard University Press, 2005.

23. Reavley NJ, Cvetkovski S, Jorm AF, et al. Help-seeking for substance use, anxiety and affective disorders among young people: results from the 2007 Australian National Survey of Mental Health and Wellbeing. Aust N Z J Psychiatry 2010;44:729-35. 